\title{
Decreased glomerular filtration rate in solderers exposed to cadmium
}

\author{
Lars Järup, Bodil Persson, Carl Gustaf Elinder
}

\begin{abstract}
Objectives-to evaluate the degree of cadmium induced glomerular impairment and to assess the dose-response relation between cadmium dose and the prevalence of glomerular dysfunction.

Methods-A comparison of glomerular filtration rates (GFR) assessed by $\mathrm{Cr}$ EDTA clearance was made in 42 solderers previously exposed to cadmium for at least five years. Blood and urine data were collected at health examinations in 1984, 1989, and 1993. Individual doses of cadmium were estimated by analysing cadmium in blood.
\end{abstract}

Results-Glomerular lesions induced by cadmium are irreversible and the GFR decreases with the degree of tubular damage. The GFR also decreases with cadmium dose and there is a dose-response relation between blood cadmium and prevalence of glomerular damage with $3.4 \%$ prevalence at blood cadmium concentrations below $50 \mathrm{nmol} / \mathrm{h}, 33 \%$ at blood cadmium concentrations between 50 and $75 \mathrm{nmol} / \mathrm{l}$ and $100 \%$ prevalence of glomerular damage when cadmium in blood exceeds $75 \mathrm{nmol} / \mathrm{h}$.

Conclusions-The kidney lesions induced by cadmium are irreversible and the prevalence of those lesions are dose dependent. There is also evidence of a dose related decrease in GFR even a long time after the end of exposure. Exposure to cadmium should therefore be minimised and workers exposed to cadmium should be examined regularly for many years after the end of exposure.

(Occup Environ Med 1995;52:818-822)

Keywords: cadmium exposure; glomerular filtration rate

Chronic exposure to cadmium causes kidney injury. ${ }^{1}$ The first sign of a renal lesion is a tubular dysfunction, characterised by an increased excretion of proteins with low molecular weight such as $\beta_{2}$-microglobulin. ${ }^{23}$ Doseresponse curves between exposure to cadmium and the prevalence of tubular proteinuria have been well established and form the basis for occupational and environmental threshold values. ${ }^{1}$ In almost all cases the proteinuria induced by cadmium is irreversible even if exposure has ended. ${ }^{24-6}$ Research on health effects of cadmium has focused on renal tubular injury. As well as the tubular proteinuria an increased prevalence of proteinuria from larger proteins such as albumin has been noticed in workers exposed to cadmium. ${ }^{7-9}$ The interpretation of the albuminuria has been debated. Does it indicate a primary glomerular damage with increased permeability of larger proteins through the glomerulus ${ }^{8}$ or is the albuminuria secondary to a decreased tubular reabsorption of the small amount of albumin normally filtered through the glomerulus? ${ }^{10}$

Glomerular damage with a decreased glomerular filtration rate (GFR) is clinically more important than an increased permeability of larger proteins. Already in 1950 Friberg reported that battery workers exposed to cadmium, as well as having proteinuria, had decreased GFR measured by inulin clearance. ${ }^{11}$ This was confirmed by Adams et al ${ }^{12}$ who measured creatinine clearance in cadmium battery workers, and more recently by other authors ${ }^{913}$ who used the serum concentration of creatinine as the estimate of glomerular function. Roels et $a l^{5}$ used serum $\beta_{2}$-microglobulin and Järup et $a l^{14}$ used ${ }^{51} \mathrm{Cr}$ EDTA clearance to measure the GFR in workers with previous exposure to cadmium. Japanese data show that people environmentally exposed to cadmium may also develop a decreased GFR. ${ }^{15}$

The quantitative relation between cadmium exposure and glomerular dysfunction has, as yet, not been well characterised and more research in this field has been asked for. ${ }^{1}$ The aim of the present study was therefore to study the relation between cadmium dose and GFR as the estimate of glomerular function.

\section{Subjects and methods}

SUBJECTS

A factory producing heat exchangers, coolers, and radiators used solders containing cadmium until 1978, when new soldering procedures were adopted. Before 1978, 68 workers had been employed at the plant for more than five years. All of them were asked to participate in the initial investigation in 1984 and 60 workers accepted. ${ }^{6}$ Of these workers 24 had tubular proteinuria $\left(\beta_{2}\right.$-microglobulin $>34$ $\mu \mathrm{g} / \mathrm{mmol}$ creatinine) and 17 workers notable tubular proteinuria $\left(\beta_{2}\right.$-microglobulin $>60$ $\mu \mathrm{g} / \mathrm{mmol}$ creatinine). In this group of 17 workers the GFR was also measured. Of these 17 workers, 16 participated in a follow up health examination in $1989 .{ }^{14}$ 
In 1993, six of the initial 60 workers were dead and, for practical reasons, two workers more than 80 years old were excluded. The remaining 52 workers were asked to participate in a new follow up performed in the same way as the previous investigations. The invitation was accepted by 46 workers ( $92 \%)$, but four of them did not complete the GFR measurements. Thus, 42 workers participated in the complete investigation. The present study included 13 of the 16 workers who participated in the 1989 investigation. One of the three workers excluded had died and the other two were over 80 in 1993. Data from the 1989 investigation about the workers who did not take part in the present study are included in the analyses of the relations between relative clearance of $\beta_{2}$-microglobulin, blood cadmium, and GFR.

\section{HEALTH EXAMINATION}

All 46 participants completed a questionnaire that included questions about present and previous health, drug use, and smoking habits. A routine physical examination was performed by two of the authors (LJ and BP). Calcium, creatinine, albumin, alkaline phosphatase, parathyroid hormone, and $\beta_{2}$-microglobulin were analysed in serum, cadmium was analysed in blood, and $\beta_{2}$-microglobulin, creatinine, calcium, cadmium, $\alpha_{1}$-microglobulin, and $\mathrm{N}$-acetyl- $\beta$-glucosaminidase (NAG) were analysed in urine. $\alpha_{1}$-Microglobulin and NAG were analysed for 45 of the 46 workers.

To prevent the degradation of $\beta_{2}$ microglobulin occurring in acidic urine $(\mathrm{pH}$ $<5.6$ ) each worker had $4 \mathrm{~g}$ of sodium bicarbonate dissolved in water the night before the morning urine was collected for protein analyses. Urine was sampled in carefully washed polyethylene bottles. Venous blood samples were collected in $10 \mathrm{ml}$ evacuated test tubes with heparin for the whole blood analyses and without additives for the analyses of serum samples. Blood and urine samples were kept at a temperature close to $0^{\circ} \mathrm{C}$ until frozen.

\section{EXPOSURE AND DOSE}

Solders containing cadmium were used at the plant from 1955 to 1978 . During the entire period, the production hall was heavily contaminated with cadmium due to a deficient ventilation system. Measurements performed in 1976 showed air concentrations ranging from 10 to $2000 \mu \mathrm{g}$ cadmium $/ \mathrm{m}^{3}$. The work environment was not improved until the cadmium containing solders were abandoned in 1978 . Individual estimates of exposure concentrations were made for each worker, classifying the exposure as low, medium, or high. ${ }^{6}$ The average air cadmium concentrations in these categories were 50,150 , and $500 \mu \mathrm{g} / \mathrm{m}^{3}$, respectively. Individual cumulative exposure estimates were computed by multiplying the air concentrations by the number of years spent at each exposure level.

Cadmium in urine is considered to mirror mainly long term exposure and is thus an estimate of the body burden. ${ }^{1016}$ Cadmium in blood is supposed to mainly reflect recent exposure, but it has also been shown that there is a component in the blood with a long half life (seven to 16 years). ${ }^{17}$ Since the half life of the fast component is around three months, the blood cadmium concentration is proportional to the body burden a few years after exposure has stopped. Cadmium in blood was not measured in 1984 (due to shortage of funding), but was measured in 1989 (16 workers) and for all participating 46 workers in the present investigation.

\section{METHODS}

The ${ }^{51} \mathrm{Cr}$-EDTA analyses were performed at the Department of Clinical Chemistry, University of Linköping, which also performed the standard chemical analyses. The specialised chemical analyses (mainly cadmium) were performed at the Department of Occupational Medicine, University of Linköping. $\beta_{2}$-Microglobulin and creatinine were measured in serum and urine, and cadmium was measured in whole blood and urine by atomic absorption spectrophotometry. ${ }^{18}$ The laboratory at the Department of Occupational Medicine participates in quality control programmes and is approved by the Swedish Board of Occupational Safety and Health. Further details of the quality control procedures can be obtained from the authors on request.

$\beta_{2}$-Microglobulin was measured by a radioimmunoassay (Phadebas, Pharmacia, Sweden). Creatinine was measured with a colorimetric method and a reaction rate analyser. The relative clearance of $\beta_{2}$-microglobulin was estimated according to this formula:

$\frac{\begin{array}{l}\text { Clearance } \\ \beta_{2}\end{array}}{\begin{array}{l}\text { Clearance } \\ \text { creatinine }\end{array}}(\%)=100 \star \frac{\begin{array}{c}\mathrm{U}-\beta_{2} \star \\ \text { serum creatinine }\end{array}}{\mathrm{S}-\beta_{2} \star}$

The GFR was measured in 1984, 1989, and 1993 with a ${ }^{51} \mathrm{Cr}$-EDTA plasma clearance technique as described by BröchnerMortensen. ${ }^{19}$ The body weights and thus the body surfaces changed significantly $(P=$ 0.004 ) from 1984 (mean $=75.8$ ) to 1993 $($ mean $=78 \cdot 5)$. The ${ }^{51} \mathrm{Cr}$-EDTA clearance was corrected to a body surface area of 1.73 $\mathrm{m}^{2}$ based on the height and body weight of the subjects and previously published reference values for the GFR. ${ }^{20}$ Granerus and Aurell calculated that the GFR decreases at 0.4 $\mathrm{ml} / \mathrm{min} /$ year before 50 years of age and at 1 $\mathrm{ml} / \mathrm{min} /$ year thereafter, in otherwise healthy people. Throughout the study the ratios between the observed and the reference GFRs were computed and used as the estimates of GFR.

\section{UNITS}

Cadmium in blood is given in $\mathrm{nmol} / 1(1 \mu \mathrm{g} / \mathrm{l}$ $=8.9 \mathrm{nmol} / \mathrm{l})$ ) and cadmium in urine is given in $\mathrm{nmol} / \mathrm{mmol}$ creatinine $(1 \mu \mathrm{g} / \mathrm{g}$ creatinine $=$ $1.0 \mathrm{nmol} / \mathrm{mmol}$ creatinine). $\beta_{2}$-Microglobulin in urine is shown as $\mu \mathrm{g} / \mathrm{mmol}$ creatinine (1 $\mu \mathrm{g} / \mathrm{g}$ creatinine $=0.112 \mu \mathrm{g} / \mathrm{mmol}$ creatinine). $\beta_{2}$-Microglobulin in serum is given in $\mathrm{mg} / \mathrm{l}$ and 
serum creatinine in $\mu \mathrm{mol} / \mathrm{l}(1 \mathrm{mg} / 100 \mathrm{ml}=$ $88 \cdot 4 \mu \mathrm{mol} / \mathrm{l})$.

\section{STATISTICAL METHODS}

Data were analysed with standard regression methods. Multivariate analyses were performed with stepwise regression, including all relevant terms. Analysis of variance was performed to assess variable differences in outcome between subgroups of study subjects. Variables with a skewed distribution were logarithmically transformed to better approximate to the normal distribution necessary for the regression analyses. The limit for significance was set at $0 \cdot 05$.

\section{Results}

In the present investigation 17 of the 46 workers $(37 \%)$ showed signs of tubular proteinuria (excreting more than $34 \mu \mathrm{g} \beta_{2}$-micoglobulin/ mmol creatinine). In 1984,19 of the 46 workers had tubular proteinuria. A few $(n=5)$ workers with raised urinary $\beta_{2}$-microglobulin in 1984 had normal excretion in 1993. On the other hand, three workers who were within the normal limit in 1984 now had tubular proteinuria.

The 46 workers were divided into three groups according to their tubular function. Relative $\beta_{2}$-microblobulin clearance of less than $0 \cdot 1 \%$ were classified as normal, relative $\beta_{2}$-microglobulin clearance of more than $0 \cdot 1 \%$ but less than $2.5 \%$ would indicate a slightly decreased reabsorption, and relative $\beta_{2}$-clearance of $2.5 \%$ or more was considered to be an indicator of highly decreased tubular reabsorption.

Table 1 presents results from the three subgroups with no, slight, and pronounced increase in relative clearance of $\beta_{2}$-microglobulin. An increased urinary excretion of cadmium, NAG, and $\alpha_{1}$-microglobulin paralleled that of $\beta_{2}$-microglobulin whereas serum and urinary calcium, serum alkaline phosphatase, and serum parathyroid hormone remained unchanged, and the GFR decreased. Analysis of variance showed significant differences in

Table 1 Analyses of blood, serum, and urine in 46 solderers exposed to cadmium: tubular function assessed by $\beta_{2}$-microglobulin clearance (values are mean (SD))

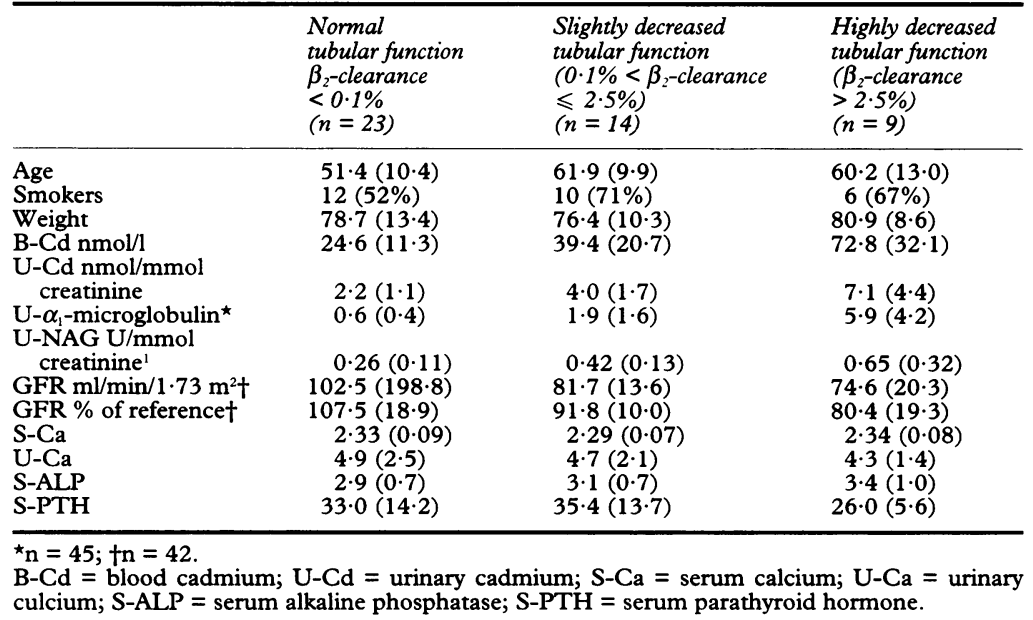

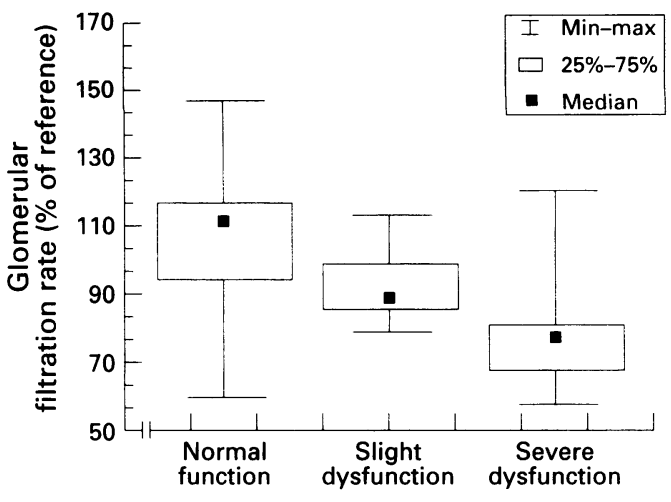

Clearance of $\beta_{2}$-microglobulin

Figure 1 Box plot in three groups of workers. Group 1 includes workers with normal tubular function, group 2 consists of workers with slightly decreased tubular function $\left(\beta_{2}\right.$-clearance $>0.1 \%$ but $\left.<2.5 \%\right)$, and group 3 includes workers with severe tubular dysfunction ( $\beta_{2}$-clearance $>2.5 \%$ ).

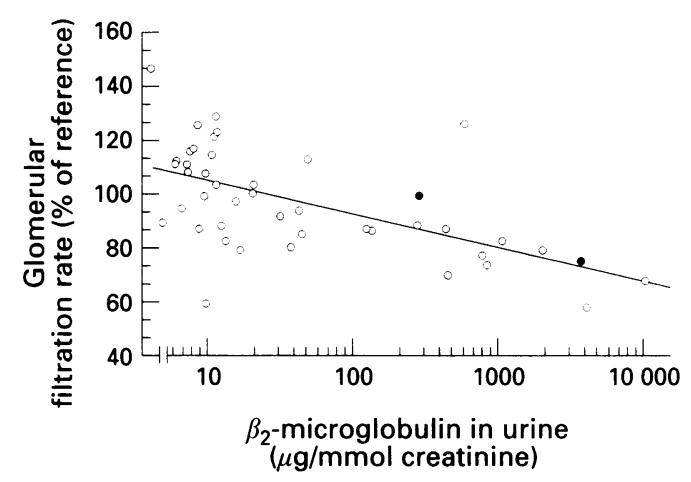

Figure 2 Glomerular filtration rate (GFR) as a function of urinary $\beta_{2}$-microglobulin. Unfilled circles represent data from the present study. Filled circles represent two workers from the 1989 study that did not participate in the present study. The regression equation is: GFR $=117.6-5.58$ * $\ln$ (urinary $\beta_{2}$-microglobulin), $(P=0.000053)$.

cadmium in blood and urine, in $\alpha_{1}$-microglobulin and NAG in urine, and in GFR between subgroups of $\beta_{2}$-microglobulin clearance. No significant associations were found between $\beta_{2}$-microglobulin clearance and the other variables analysed (serum cadmium, urinary calcium, serum alkaline phosphatase, and serum parathyroid hormone).

There was a correlation between the degree of tubular dysfunction and decreased glomerular filtration rate (fig 1). The median values of GFR as a percentage of the age specific reference values were $110 \cdot 0,88 \cdot 1$, and 77.4 respectively in the three different groups of $\beta_{2}$-microglobulin clearance. The relation between the GFR and relative clearance of $\beta_{2}$ microglobulin was computed, yielding the regression line:

GFR $=87.93-5.71 \star \ln \left(\beta_{2}\right.$-microglobulin clearance), $\mathrm{P}=0.000081$.

Figure 2 shows the relation between the GFR and urinary $\beta_{2}$-microglobulin.

There was a significant correlation between cumulative exposure to cadmium in work room air and the excretion of cadmium in urine with the regression equation: 


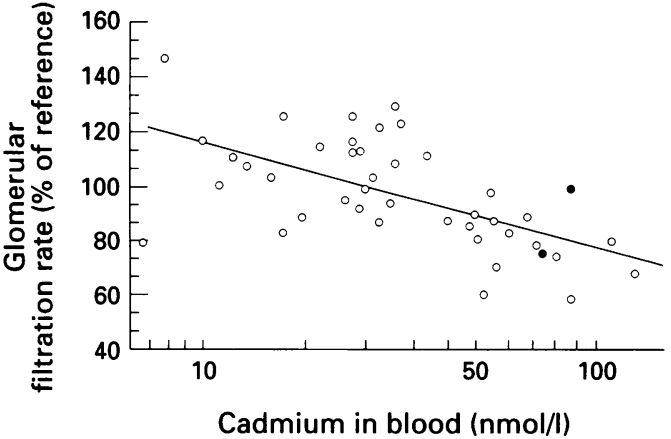

Figure 3 Glomerular filtration rate (GFR) as a function of blood cadmium. Unfilled circles represent data from the present study. Filled circles represent two workers from the 1989 study that did not participate in the present study. The regression equation is: GFR $=155.0-16.7^{\star} \ln$ cadmium in blood, $P=0.000015$ ).

Table 2 Dose-response relation between cadmium in blood and workers with decreased GFR (defined as GFR $<80 \%$ of reference)

\begin{tabular}{lllc}
\hline $\begin{array}{l}\text { Blood cadmium } \\
\text { (nmolll) }\end{array}$ & $\begin{array}{l}\text { Cases } \\
\text { GFR }<80 \% \\
\text { of reference }\end{array}$ & Total & $\begin{array}{l}\text { Response } \\
\text { (\%) }\end{array}$ \\
\hline$<50$ & 1 & 29 & $3 \cdot 4$ \\
$50-<75$ & 3 & 9 & 33.3 \\
$\geqslant 75$ & 4 & 4 & 100.0 \\
\hline
\end{tabular}

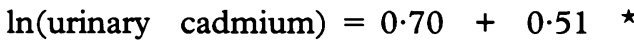
$\ln$ (cumulative exposure), $\quad r=0.54, \quad \mathrm{P}=$ 0.0001 .

There was a also a good correlation between cumulative exposure to cadmium in work room air and blood cadmium as evident from the regression equation:

$\ln ($ blood cadmium) $=3.18-0.36 \star$ $\ln$ (cumulative exposure), $\quad r=0.44, \quad \mathrm{P}=$ 0.002 .

To assess the relation between cumulative exposure to cadmium and the GFR we first used the estimates of cumulative cadmium in air and the resulting regression equation was:

GFR $=102.3-6.94 \star \ln$ (cumulative exposure), $r=0.29, \mathrm{P}=0.061$ (with GFR as a percentage of reference value).

We then used blood cadmium as the dose estimate, and fig 3 shows the relation between cadmium in blood and GFR (as a percentage of reference value).

Setting $80 \%$ of the reference value as the cut off point for decreased GFR there was an apparent dose-response pattern between blood cadmium and glomerular dysfunction (table 2).

We also used the measured values of GFR $\left(\mathrm{ml} / \mathrm{min} / 1 \cdot 73 \mathrm{~m}^{2}\right)$ adding age to the multiple regression with similar results to when the reference values were used for age adjustment. The addition of smoking to the regression equations did not change the results significantly.

\section{Discussion}

The critical effect of exposure to cadmium is renal tubular dysfunction, which has been thoroughly studied by several authors. The clinically more important glomerular damage has been much less examined and doseresponse data are very limited. On two previous occasions a subgroup of workers (17 and 16) from the same population was studied..$^{914}$

In the initial investigation in 1984, 24 of the 60 workers $(40 \%)$ had tubular proteniuria $\left(\beta_{2}-\right.$ microglobulin $>34 \mu \mathrm{g} / \mathrm{mmol}$ creatinine) and 17 of these 24 workers had pronounced tubular proteinuria $\left(\beta_{2}\right.$-microglobulin $>60 \mu \mathrm{g} / \mathrm{mmol}$ creatinine). In the present study, five of these 24 workers had normal urinary excretion of $\beta_{2}$ microglobulin. In the group with notable tubular proteinuria $\left(\beta_{2}\right.$-microglobulin $>60$ $\mu \mathrm{g} / \mathrm{mmol}$ creatinine) in 1984 , only one worker had a normal value in 1989 (and in 1993). The tubular proteinuria in these five workers was most likely due to other causes than cadmium. The remaining workers still showed signs of tubular proteinuria and another three workers had developed tubular dysfunction since the previous examination. Thus, 17 of 46 workers (37\%) excreted more than $34 \mu \mathrm{g}$ $\beta_{2}$-microglobulin $/ \mathrm{mmol}$ creatinine in this study confirming earlier studies that have shown that the tubular damage induced by cadmium was irreversible in most cases. A more detailed discussion of the tubular damage including other markers of tubular dysfunction $\left(\alpha_{1}\right.$-microglobulin and NAG) will be presented elsewhere.

The 1984 investigation showed a weak but significant correlation between loss of tubular reabsorption (estimated by $\beta_{2}$-microglobulin clearance) and GFR ( $<<0.05, r=-0.47)$. In the 1989 follow up the regression slope was less pronounced and the correlation was not significant $(r=-0.30)$. In the present study, the regression slope was again more pronounced and clearly significant $(P=0.0049$, $r=-0.43)$. The relation was further strengthened when $\beta_{2}$-microglobulin clearance was logarithmically transformed $(P=$ $0.00081)$. This finding is in agreement with previous studies that have shown a correlation between loss of tubular function and glomerular damage as measured by endogenous creatinine clearance. ${ }^{21}$ Controlling for age, the regression slope $\beta_{2}$-microglobulin changed only marginally and the correlation remained significant $(P=0.00031)$.

Table 1 shows that men with slightly and highly decreased tubular function (increased $\beta_{2}$-microglobulin clearance) had decreased GFR and increased urinary concentrations of cadmium, NAG, and $\alpha_{1}$-microglobulin compared with those with a normal clearance. Figure 1 also shows the trend in decreasing GFR with increasing $\beta_{2}$-microglobulin clearance. There is a significant decrease in GFR between the group with normal $\beta_{2}$-microglobulin clearance and the group with a slight tubular dysfunction. The difference between the workers with a slight dysfunction and the group with a highly decreased function does not reach significance at the $95 \%$ level and is barely siginificant at the $90 \%$ level $(\mathrm{P}=$ 0.092 , confidence interval 0.29 to $22 \cdot 6$ )) Figure 2 shows the relation between urinary $\beta_{2}$-microglobulin and GFR, where data for two workers from the 1989 investigation, who 
did not participate in the present study, have been added to enhance the analysis. There was a clear and significant relation $(P=$ 0.000053 ) between $\beta_{2}$-microglobulin in urine and GFR.

There was, however, no evidence of a decreased GFR in the group of workers with normal tubular function, even though a few people in this group were below the reference value, which is to be expected for statistical reasons.

Cadmium accumulation in the kidney is likely to be the cause of tubular damage with proteinuria $\left(\beta_{2}\right.$-microglobulinuria and $\alpha_{1}$ microglobulinuria), enzymuria (NAG), and decreased GFR. On the other hand there was no evidence of effects from cadmium on the calcium and bone metabolism as urinary calcium, serum calcium, serum parathyroid hormone and serum alkaline phosphatase could not be significantly related to tubular damage or cumulative cadmium dose. In 12 workers the GFRs have been measured on three occations (1984, 1989, and 1993). No significant changes in the GFR were found over time, also after adjustment for age. No improvement of the glomerular function could thus be found even several years after cadmium exposure had stopped. The drop in GFR caused by cadmium therefore seems to be irreversible.

Cumulative exposure to cadmium in air is often used as an estimation of dose in occupational epidemiology. The internal cadmium dose, however, may vary considerably between people with different personal habits, absorption capacity, or metabolic functions. Therefore it is preferable to use internal dose estimates when feasible. It has previously been shown that there is a good correlation between cumulative cadmium in work room air and urinary cadmium excretion ${ }^{22}$ and this was confirmed in the present study. Urinary cadmium values of workers with tubular dysfunction is, however, often higher than predicted from the regression line and this may lead to an altered dose-response relation. ${ }^{23}$ Cadmium in blood, on the other hand, is not affected by the tubular function and blood measurements made many years after the end of exposure are therefore most likely to be good estimates of the cadmium body burden.

There was a clear dose-effect relation between blood cadmium and decreasing glomerular filtration rate (fig 3). At a blood cadmium concentration of $100 \mathrm{nmol} / 1$ there was a decrease in GFR to $80 \%$ of the reference concentration. Furthermore, there was an apparent dose-response relation between blood cadmium and the prevalence of decreased GFR (defined as less than $80 \%$ of the reference value, table 2). Although the numbers are fairly small, the indication of an increase in prevalence is obvious.

In a previous investigation of the present study group it was reported that men with high urinary cadmium $(>6.3 \mathrm{nmol} / \mathrm{mmol}$ creatinine) more often had a history of renal stones than less exposed workers. ${ }^{9}$ In a study of battery workers exposed to cadmium we have shown that there is a dose dependent increase in incidence of renal stones. ${ }^{24} \mathrm{~A}$ reanalysis of the incidence of renal stones in the present study group is ongoing and will be presented elsewhere.

In conclusion, the tubular and glomerular kidney lesions induced by cadmium are irreversible. The prevalence of these lesions are dose dependent.

The study has been carried out with funding from the Swedish Work Environment Fund. We thank Ms Sylwia Flato for performing the NAG analyses.

1 World Health Organisation. Cadmium. Geneva: WHO, 992. (Environmental health criteria 134.)

2 Piscator M. Proteinuria in chronic cadmium poisoning. III. Electrophoretic and imunoelectrophoretic studies on urinary proteins from cadmium workers, with special reference to the excretion of low molecular weight proteins. Arch Environ Health 1966;12:235-44.

3 Kjellström T, Evrin PE, Rahnster B. Dose-response analysis of cadmium-induced tubular proteinuria: a study of urinary $\beta_{2}$-microglobulin excretion among workers in a battery factory. Environ Res 1977;13:303-17.

4 Roels H, Djubgang J, Buchet JP, Bernard A, Lauwerys R Evolution of cadmium-induced renal dysfunction in workers removed from exposure. Scand 7 Work Environ Health 1982;8:191-200.

5 Roels HA, Lauwerys RR, Buchet JP, Bernard AM, Vos A Oversteyns $M$. Health significance of cadmium induced Oversteyns $M$. Health significance of cadmium induced 1989;46:755-64.

6 Elinder CG, Edling C, Lindberg E, Kågedal B, Vesterberg O. $\beta_{2}$-Microglobulinuria among workers previously exposed to cadmium: follow-up and dose-response analyses. Am $\mathcal{F}$ Ind Med 1985;8:553-64.

7 Bernard A, Roels H, Hubermont G, Buchet JP, Masson PL, Lauwerys RR . Characterization of the proteinuria in cadmium-exposed workers. Int Arch Occup Environ Health 1976;38:19-30.

8 Bernard A, Buchet JP, Roels H, Masson P, Lauwerys R. Renal excretion of proteins and enzymes in workers exposed to cadmium. Eur $f$ Clin Invest 1979;9:1 1-22.

9 Elinder CG, Edling C, Lindberg E, Kågedal B, Vesterberg $O$. Assessment of renal function in workers previously exposed to cadmium. Br f Ind Med 1985;42:754-60.

10 Friberg L, Elinder CG, Kjellström T, Nordberg GF Cadmium and health: a toxicological and epidemiological appraisal. Boca Raton, FL: CRC Press 1986, 2.

11 Friberg L. Health hazards in the manufacture of alkaline accumulators with special reference to chronic cadmium poisoning. Acta Med Scand 1950;240(suppl):1-124.

12 Adams RG, Harrison JF, Scott P. The development of cadmium-induced proteinuria, impaired renal function and osteomalacia in alkaline battery worker. $Q \ngtr \mathrm{Med} 1969$; 38:425-43.

13 Kido $T$, Nogawa $K$, Ishizaki $M$, Honda $R$, Tsuritani $I$ Yamada $\mathrm{Y}$, et al. Long-term observation of serum creatinine and arterial blood $\mathrm{pH}$ in persons with cadmiuminduced renal dysfunction. Arch Environ Health 1990, 45:35-41.

14 Järup L, Persson B, Edling C, Elinder CG. Renal function impairment in workers previously exposed to cadmium. Nephron 1993;64:75-81.

15 Nogawa K. Biologic indicators of cadmium nephrotoxicity in persons with low-level cadmium exposure. Environ persons with low-level cadmin Perspect 1984;54:163-9.

16 Elinder C-G, Friberg L, Nordberg GF, Kjellström T, Oberdoerster G. Biological monitoring of metals. Chemical Oberdoerster G. Biological monitoring of metals. Chemical
safety monographs. International programme on chemical safety monographs. International programme on chemical safety.

17 Järup L, Rogenfelt A, Elinder CG, Nogawa K, Kjellström $\mathrm{T}$. Biological half-time of cadmium in the blood of workers after cessation of exposure. Scand $\mathcal{f}$ Work Environ Health 1983;9:327-31.

18 Lagesson V, Andrasko L. Direct determination of lead and cadmium in blood and urine by flameless atomic absorption spectrophotometry. Clin Chem 1979;25:1948-53.

19 Bröchner-Mortensen J. A simple method for the determination of glomerular filtration rate. Scand $¥$ Clin Lab Invest 1972;30:271-4.

20 Granerus G, Aurell M. Reference values for ${ }^{51} \mathrm{Cr}$-EDTA clearance as a measure of glomerular filtration rate. Scand clearance as a measure of glomerular

21 Piscator $M$. Long-term observations on tubular and glomerular function in cadmium-exposed persons. glomerular function in cadmium-exp
Environ Health Perspect 1984;54:175-9.

22 Järup L. Dose response relations for occupational exposure to arsenic and cadmium. Arbete Och Hälsa 1992;38:1-50.

23 Järup L, Elinder CG. Dose-response relations between urinary cadmium and tubular proteinuria in cadmium exposed workers. Am $\mathcal{f}$ Ind Med 1994;26:759.

24 Järup L, Elinder CG. Incidence of renal stones among cadmium exposed battery workers. $\mathrm{Br} F$ Ind Med 1993;50 598-602. 